\title{
Papers
}

\section{Effect of low doses of ionising radiation in infancy on cognitive function in adulthood: Swedish population based cohort study}

Per Hall, Hans-Olov Adami, Dimitrios Trichopoulos, Nancy L Pedersen, Pagona Lagiou, Anders Ekbom, Martin Ingvar, Marie Lundell, Fredrik Granath

\begin{abstract}
Objective To determine whether exposure to low doses of ionising radiation in infancy affects cognitive function in adulthood.

Design Population based cohort study.

Setting Sweden.

Participants 3094 men who had received radiation for cutaneous haemangioma before age 18 months during 1930-59.
\end{abstract}

Main outcome measures Radiation dose to frontal and posterior parts of the brain, and association between dose and intellectual capacity at age 18 or 19 years based on cognitive tests (learning ability, logical reasoning, spatial recognition) and high school attendance.

Results The proportion of boys who attended high school decreased with increasing doses of radiation to both the frontal and the posterior parts of the brain from about 32\% among those not exposed to around $17 \%$ in those who received $>250$ mGy. For the frontal dose, the multivariate odds ratio was 0.47 (95\% confidence interval 0.26 to 0.85 , $\mathrm{P}$ for trend 0.0003 ) and for the posterior dose it was 0.59 (0.23 to $1.47,0.0005)$. A negative dose-response relation was also evident for the three cognitive tests for learning ability and logical reasoning but not for the test of spatial recognition.

Conclusions Low doses of ionising radiation to the brain in infancy influence cognitive abilities in adulthood.

\section{Introduction}

Ionising radiation may impair the developing human brain and adversely affect cognitive processes, as documented among children exposed in utero after the bombing of Hiroshima and Nagasaki or treated with radiation for ringworm of the scalp. ${ }^{1-5}$ Evidence also comes from young children treated for leukaemia or brain tumours ${ }^{6-9}$; but in these studies it is difficult to distinguish the effect of radiation from that of underlying diseases, concomitant surgery or chemotherapy, or hormonal abnormalities. ${ }^{7}$ Existing data are based mostly on high doses of ionising radiation ( $\geq 1 \mathrm{~Gy}$ ), therefore little is known about the effects of low doses of radiation or a possible threshold value. Also inadequately documented is the effects of age at exposure. Lack of such evidence is of concern because modern imaging techniques such as computed tomography, which deliver high doses of ionising radiation, are increasingly being used in even young children after minor head trauma. The dose delivered to the brain of an infant during computed tomography of the skull is around $120 \mathrm{mGy} .^{10}$
We analysed cognitive function in a large population based cohort of men at the time of military enlistment who had received low dose ionising radiation for cutaneous haemangioma before age 18 months. Based on previous experience, we hypothesised that damage to the frontal part of the brain would have a more severe effect on mental capacity than damage to the posterior part. ${ }^{11}$

\section{Participants and methods}

Our cohort comprised all boys treated by radiotherapy for cutaneous haemangioma aged under 18 months at the Karolinska University Hospital in Stockholm. This cohort has been described in detail previously. ${ }^{12-17}$

Around $95 \%$ of Swedish men aged 18 or 19 years are tested before military service. During the period of our study, about $2 \%$ of the men tested were exempted from military service for medical or psychological reasons. ${ }^{18}$ We were given permission to search the Swedish war archives.

From the military register we obtained information on age at enlistment, education, number of siblings, birth order, father's occupation, and cognitive test results. Father's occupation, a proxy for socioeconomic status, was categorised into four groups: unknown and farmers, blue collar workers, low level white collar workers, and high level white collar workers. Categorisation was based on the socioeconomic index, which takes education into consideration. ${ }^{19}$

\section{Radiation treatment and dosimetry}

Treatment for cutaneous hemangioma before age 18 months included $\beta$ rays, $\gamma$ rays, or $x$ rays. During the study period, the most common treatment was with applicators containing radium-226. ${ }^{172} \mathrm{X}$ ray treatments mainly involved contact therapy ( $\leq 60 \mathrm{kVp}$, half value layer $<1.0 \mathrm{~mm}$ aluminium). Some children were treated more than once, either by receiving several treatments for one hemangioma or by receiving individual treatments for several haemangiomas.

The dose from treatments with ${ }^{26} \mathrm{Ra}$ needles or tubes in glass capsules was measured with the original applicators on a child phantom. ${ }^{17}{ }^{20}$ For all other kinds of treatments we used the original depth-dose curves and tables. We adjusted the distance between the source of the rays and the brain according to the child's age and size at treatment. The location of the haemangioma was estimated by means of photographs and sketches in the treatment records. The division into frontal and posterior lobes of the brain was based on the functional specialisation of these lobes. ${ }^{21}$ 
Table 1 Average and median absorbed doses of ionising radiation to frontal and posterior parts of brain in relation to location of cutaneous haemangioma

\begin{tabular}{|c|c|c|c|c|}
\hline \multirow[b]{2}{*}{ Location of haemangioma } & \multirow[b]{2}{*}{ No of patients } & \multicolumn{2}{|c|}{ Mean/median dose (mGy) to part of brain (maximum dose, Gy) } & \multirow[b]{2}{*}{ Average } \\
\hline & & Frontal & Posterior & \\
\hline Scalp & 552 & 172/150 (2.8) & $121 / 190(1.8)$ & $147 / 120$ \\
\hline Face & 642 & $79 / 60(2.4)$ & $50 / 40(0.4)$ & $64 / 50$ \\
\hline Other parts of body & 1675 & $15 / 10(0.3)$ & $16 / 10(0.3)$ & $16 / 10$ \\
\hline Mean (median) dose (mGy) & & $60(20)$ & $44(20)$ & $52(20)$ \\
\hline
\end{tabular}

\section{Outcome measures}

During 1930-59, an average grade entitled students aged 15 or 16 year olds to enter the equivalent of high school or to take A levels. Members of the cohort were categorised as either those who had enrolled at high school at the time of military tests or those who had not. We could not ascertain whether high school had been successfully completed, because this usually took place after military enlistment. However, most of those still attending high school at 18 years would be expected to pass the high school examination.

The Swedish psychological tests for military enlistment have been used for more than 50 years, with some changes. ${ }^{18} 22$ They include tests of general instructions, concept discrimination, technical comprehension, and spatial recognition. The first three of these are believed to measure general verbal ability and to be sensitive to education. We analysed the general instructions and concept discrimination tests as one entity (using the average score) as they gave similar results. In the test for spatial recognition, logical reasoning is scored. All test scores assigned during one particular year were standardised to a mean of 5 and a range from 1 to 9 .

\section{Statistical methods}

We used logistic regression to model the probability of having entered the equivalent of high school using the categorical explanatory variables for estimated absorbed dose to brain, age (months) at treatment $(0-7,>7-12, \geq 12)$, number of siblings $(0$, $1,2,>2)$, father's occupation, and year of military test. Doses $(\mathrm{mGy})$ were divided into five categories: 0, 1-20, > 20-100, $>100-250$, and $>250$. Results are presented as odd ratios with $95 \%$ confidence intervals. We used likelihood ratio tests to assess the significance of the explanatory variables.

Differentiation between an individual's logical reasoning and other abilities was computed as the difference between the spatial recognition test and the average of the three remaining tests. The differences were also tested by analysis of variance with the explanatory variables used in the logistic regression of high school attendance. We present crude means and least square means (means adjusted for covariates and the unbalanced design), with standard errors.

\section{Results}

During 1930-59, 4577 boys aged under 18 months received radiotherapy for cutaneous haemangioma at the Karolinska University Hospital, Stockholm. Information was missing on the names and dates of birth for four children and dose of radiation for one child, and two children were lost to follow up. Hence 4570 men in the original cohort were available for follow up (figure). We excluded 1439 men tested after 1968 because the retrieval of data was administratively complicated then, and we excluded 37 men tested before 1954 because the tests of cognitive function changed after that time. The military records of 220 men could not be found, and the test results of five men were missing. Information was missing on education for 53 boys and number of siblings for another 265, leaving 2551 boys for analy- sis of high school attendance. We excluded 160 men from analyses of cognitive function as they were tested during 1954-8 before the battery of cognitive tests was expanded from three to four, making it difficult to compare their results with those of the 2869 men who took the test during 1959-68. In addition, we excluded 180 boys without information on fathers' occupation. This left 2211 for analysis of cognitive function.

The mean number of haemangiomas per child was 1.5 (range 1-16). Overall, 49\% $(\mathrm{n}=1380)$ of the men were irradiated when aged under 6 months, $39 \%(\mathrm{n}=1098)$ at 6 - 11 months, and $12 \%(n=338)$ at $12-17$ months. The mean age of the men at first treatment was 7 months (median 6 months). The average estimated absorbed dose to the brain was 52 mGy (median 20 $\mathrm{mGy}$, range $0-2800 \mathrm{mGy}$ ) and the largest contribution came from irradiation of haemangiomas in the head region (table 1). The average and median dose to the frontal part of the brain was slightly higher than to the posterior part. An estimated dose of $100 \mathrm{mGy}$ or more was delivered to the frontal part of the brain in $661 / 2816(23.5 \%)$ men and to the posterior part in 384/2816 (13.6\%; table 2).

\section{High school attendance}

A decrease in high school attendance was seen in all socioeconomic groups at radiation doses greater than $100 \mathrm{mGy}$ when compared with the lowest dose of 1-20 mGy (table 2). No consistent difference was seen between the two lowest dose categories (1-20 $\mathrm{mGy}$ and >20-100 mGy); however, the increment of exposure was limited, with median values of only 0 and $30-40 \mathrm{mGy}$.

We found an overall statistically significant decreasing probability of attending high school in relation to radiation dose

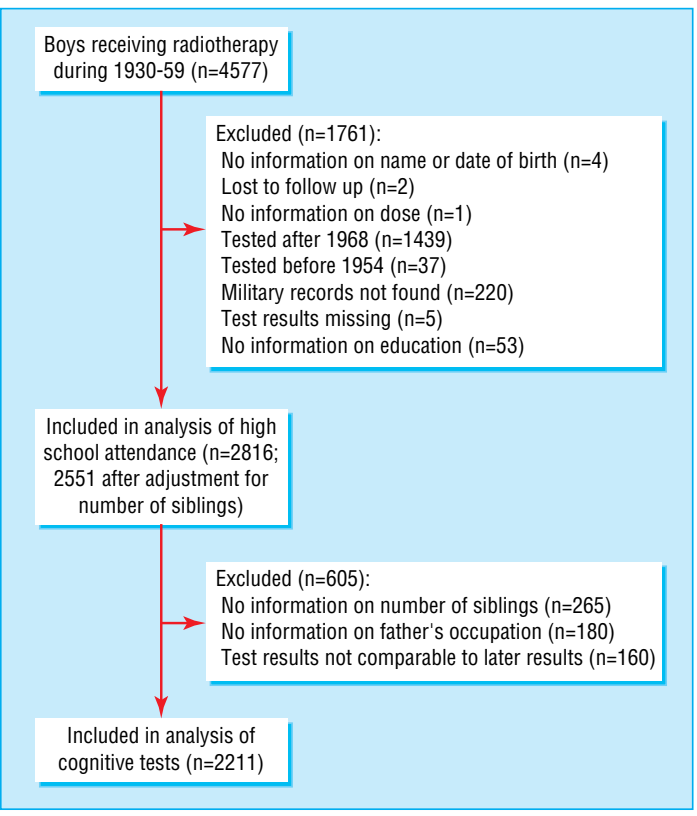

Flow of patients through trial 
Table 2 High school attendance in relation to part of brain receiving dose of radiation and father's socioeconomic status in cohort of 2816 Swedish men irradiated for cutaneous haemangioma when aged under 18 months. Values are numbers (percentages) unless stated otherwise

\begin{tabular}{|c|c|c|c|c|c|}
\hline \multirow[b]{2}{*}{ Dose (mGy) to brain (median) } & \multirow[b]{2}{*}{ No in cohort (n-2816) } & \multirow{2}{*}{$\begin{array}{l}\text { Blue collar worker } \\
\qquad(\mathrm{n}=1072)\end{array}$} & \multicolumn{2}{|c|}{ White collar worker } & \multirow{2}{*}{$\begin{array}{l}\text { Insufficient information } \\
\qquad(\mathrm{n}=218)\end{array}$} \\
\hline & & & Low level $(\mathrm{n}=897)$ & High level $(n=629)$ & \\
\hline \multicolumn{6}{|l|}{ Frontal dose } \\
\hline 0 & $793(32.4)$ & $269(11.9)$ & $266(35.3)$ & $206(60.7)$ & $52(11.5)$ \\
\hline $1-20(10)$ & $505(33.1)$ & $189(12.7)$ & $163(41.7)$ & $121(59.5)$ & $32(9.4)$ \\
\hline$>20-100(30)$ & $857(29.2)$ & $345(11.3)$ & $272(33.1)$ & $183(61.2)$ & $57(15.8)$ \\
\hline$>100-250$ (140) & $545(21.6)$ & $226(8.4)$ & $160(25.6)$ & $97(52.6)$ & $62(11.3)$ \\
\hline$>250(300)$ & $116(17.3)$ & $43(7)$ & $36(16.7)$ & $22(50)$ & $15(0)$ \\
\hline \multicolumn{6}{|l|}{ Posterior dose } \\
\hline 0 & $892(32.5)$ & $304(12.2)$ & $297(36.4)$ & $231(58.9)$ & $60(15)$ \\
\hline $1-20(10)$ & $382(32.2)$ & $138(13)$ & $129(38.8)$ & $91(59.3)$ & $24(4.2)$ \\
\hline$>20-100(40)$ & $1158(28.7)$ & $470(10.9)$ & $348(33.1)$ & $250(62)$ & $90(12.2)$ \\
\hline$>100-250(140)$ & $343(17.5)$ & $144(6.3)$ & $112(22.3)$ & $51(45.1)$ & $36(8.3)$ \\
\hline$>250(300)$ & $41(17.1)$ & $16(12.5)$ & $11(9.1)$ & $6(50)$ & $8(12.5)$ \\
\hline
\end{tabular}

Table 3 Odds ratios and $95 \%$ confidence intervals of high school attendance in relation to dose of radiation to the brain in 2551 Swedish men irradiated for cutaneous haemangioma aged when aged under 18 months

\begin{tabular}{|c|c|c|}
\hline Dose to brain (mGy) & Crude odds ratio $(95 \% \mathrm{Cl})$ & Multivariate* odds ratio $(95 \% \mathrm{CI})$ \\
\hline \multicolumn{3}{|l|}{ Frontal dose } \\
\hline 0 & 1.00 & 1.00 \\
\hline $0-20$ & $1.03(0.81$ to 1.31$)$ & 1.14 (0.86 to 1.51$)$ \\
\hline$>20-100$ & $0.86(0.70$ to 1.06$)$ & $1.06(0.88$ to 1.36$)$ \\
\hline$>100-250$ & $0.58(0.45$ to 0.74$)$ & $0.70(0.52$ to 0.94$)$ \\
\hline$>250$ & 0.43 (0.26 to 0.72$)$ & $0.47(0.26$ to 0.85$)$ \\
\hline Odds ratio per $50 \mathrm{mGy}$ & 0.86 (0.81 to 0.91$)$ & $0.89(0.83$ to 0.95$)$ \\
\hline$P$ for trend $\dagger$ & $<0.0001$ & 0.0003 \\
\hline \multicolumn{3}{|l|}{ Posterior dose } \\
\hline 0 & 1.00 & 1.00 \\
\hline $1-20$ & $0.99(0.76$ to 1.27$)$ & $1.06(0.79$ to 1.43$)$ \\
\hline$>20-100$ & 0.83 (0.69 to 1.01$)$ & 0.99 (0.79 to 1.24$)$ \\
\hline$>100-250$ & $0.44(0.32$ to 0.60$)$ & 0.55 (0.38 to 0.79$)$ \\
\hline$>250$ & 0.43 (0.19 to 0.98$)$ & $0.54(0.23$ to 1.47$)$ \\
\hline Odds ratio per $50 \mathrm{mGy}$ & 0.81 (0.75 to 0.88$)$ & 0.86 (0.79 to 0.93$)$ \\
\hline $\mathrm{P}$ for trend $\dagger$ & $<0.0001$ & 0.0005 \\
\hline
\end{tabular}

${ }^{*}$ Adjusted for number of siblings, age at treatment, father's occupation, and year of test.

tBased on dose treated as continuous variable.

(table 3). Adjustment for potential confounders changed risk estimates only marginally. The probability of attending high school was reduced by around $50 \%$ in greater than $100 \mathrm{mGy}$ category compared with the 1-20 mGy, and it decreased by $11-14 \%$ per $50 \mathrm{mGy}$ increment in dose in the multivariate analyses. We found no appreciable difference in the dose-response relation between frontal and posterior dose of radiation to the brain. The relative decrease in high school attendance was greater for sons of low level white collar workers. The dose-response relations in the three socioeconomic classes, however, were not significantly different from each other when dose was used as a continuous variable (table 4 ).

The statistical power to separate the effect of dose to the frontal and posterior part of the brain was low due to a high degree of colinearity between dose estimates $(r=0.84$, $\mathrm{P}<0.0001)$. The dose to the frontal part of the brain provided a slightly better fit to the data than did the dose to the posterior part. Furthermore, adding frontal and posterior doses did not significantly improve the fit of the model $(\mathrm{P}=0.29)$.

To explore a possible modifying effect by age at treatment, we stratified the men into those treated at age 6 months and those treated at age 6-18 months. We found no evidence of a difference between these strata in the strength of association between frontal dose and probability of attending high school. When radiation dose was analysed as a continuous variable, the change in risk per $50 \mathrm{mGy}$ was $9 \%$ for age 6 months and 14\% for age 6-18 months. Similar results were obtained when we analysed posterior dose (data not shown).

\section{Cognitive tests}

In univariate analyses, a significant dose-response relation was seen for all cognitive tests except spatial recognition (results not shown). Frontal dose had a stronger association with the outcome variables than did posterior dose and was therefore considered in further analyses. In the multivariate setting we took into consideration age at treatment, number of siblings, and year of test. Significant trends of decreasing test results with increasing dose were seen for concept discrimination and general instruction $(\mathrm{P}=0.03)$ and technical comprehension $(\mathrm{P}=0.003)$. No trend was seen for spatial recognition $(\mathrm{P}=0.50$; table 5).

To investigate whether the difference in dose-response between cognitive tests reflecting learning ability and logical reasoning was consistent within the men, we used as a response variable the individual difference between the results of the spatial recognition test and the average of the three tests. The unadjusted individual discrepancy between the different tests increased significantly with dose (table $6, \mathrm{P}=0.0002$ ). Furthermore, both the significance and the estimated changes per unit dose remained essentially unchanged after adjustment not only 
Table 4 Multivariate analysis of high school attendance in relation to radiation dose to brain in 2371 Swedish men irradiated for cutaneous haemangioma when aged under 18 months, stratified by father's socioeconomic status. Values are odds ratios (95\% confidence intervals) unless stated otherwise

\begin{tabular}{|c|c|c|c|}
\hline \multirow[b]{2}{*}{ Dose to brain (mGy) } & \multirow[b]{2}{*}{ Blue collar worker } & \multicolumn{2}{|c|}{ White collar worker } \\
\hline & & Low level & High level \\
\hline \multicolumn{4}{|l|}{ Frontal dose: } \\
\hline 0 & 1.00 & 1.00 & 1.00 \\
\hline $1-20$ & 1.20 (0.65 to 2.23$)$ & 1.39 (0.89 to 2.15$)$ & 0.93 (0.57 to 1.53$)$ \\
\hline$>20-100$ & 1.20 (0.69 to 2.09$)$ & 0.99 (0.67 to 1.46$)$ & 1.26 (0.80 to 1.98$)$ \\
\hline$>100-250$ & 0.83 (0.43 to 1.60$)$ & 0.59 (0.37 to 0.95$)$ & 0.72 (0.42 to 1.22$)$ \\
\hline$>250$ & 0.84 (0.23 to 3.05$)$ & 0.32 (0.12 to 0.89 ) & 0.67 (0.26 to 1.73$)$ \\
\hline Odds ratio per 50 mGy & 0.95 (0.83 to 1.09$)$ & 0.82 (0.74 to 0.92$)$ & 0.91 (0.83 to 1.01) \\
\hline$P$ for trend $\dagger$ & 0.46 & 0.0003 & 0.03 \\
\hline \multicolumn{4}{|l|}{ Posterior dose: } \\
\hline 0 & 1.00 & 1.00 & 1.00 \\
\hline $1-20$ & 1.13 (0.58 to 2.20$)$ & 1.10 (0.70 to 1.75$)$ & 1.12 (0.66 to 1.92$)$ \\
\hline$>20-100$ & 1.06 (0.64 to 1.76$)$ & 0.86 (0.60 to 1.23 ) & 1.31 (0.87 to 1.96$)$ \\
\hline$>100-250$ & 0.67 (0.30 to 1.48) & 0.49 (0.29 to 0.85$)$ & 0.56 (0.29 to 1.09) \\
\hline$>250$ & 2.06 (0.41 to 10.45$)$ & 0.14 (0.02 to 1.15$)$ & 0.92 (0.17 to 5.12$)$ \\
\hline Odds ratio per 50 mGy & $0.97(0.80$ to 1.17$)$ & 0.77 (0.66 to 0.89$)$ & 0.91 (0.79 to 1.04$)$ \\
\hline $\mathrm{P}$ for trend $\dagger$ & 0.72 & 0.0001 & 0.11 \\
\hline
\end{tabular}

${ }^{*}$ Adjusted for number of siblings, age at treatment, and year of test.

†Based on dose treated as continuous variable.

Table 5 Mean test results adjusted for number of siblings, age at treatment, and year of test in relation to radiation dose in 2211 Swedish men irradiated for cutaenous haemangioma when aged under 18 months. Values are mean (standard error) unless stated otherwise

\begin{tabular}{|c|c|c|c|c|}
\hline \multirow[b]{2}{*}{ Dose to frontal part of brain (mGy) } & \multirow[b]{2}{*}{ No } & \multicolumn{3}{|c|}{ Category of military test } \\
\hline & & Concept discrimination and general instruction & Technical instruction & Spatial recognition \\
\hline 0 & 638 & $5.50(0.07)$ & $5.45(0.08)$ & $5.36(0.09)$ \\
\hline $1-20$ & 400 & $5.67(0.09)$ & $5.40(0.10)$ & $5.37(0.11)$ \\
\hline$>20-100$ & 677 & $5.63(0.07)$ & $5.37(0.08)$ & $5.49(0.08)$ \\
\hline$>100-250$ & 410 & $5.42(0.09)$ & $5.31(0.10)$ & $5.48(0.10)$ \\
\hline$>250$ & 86 & $5.34(0.18)$ & $4.78(0.21)$ & $5.44(0.21)$ \\
\hline$P$ for trend ${ }^{*}$ & & 0.03 & 0.003 & 0.50 \\
\hline
\end{tabular}

*Based on mean value in each strata and dose treated as continuous variable.

Table 6 Average difference between scores on spatial recognition test and on combined tests in 2211 Swedish men irradiated for cutaneous haemangioma when aged under 18 months. Values are changes in mean (SE) scores, unless stated otherwise; reference value for regression is dose of 0 mGy

\begin{tabular}{|c|c|c|c|}
\hline Dose to brain (mGy) & Crude & Adjusted $^{*}$ & Adjusted $\dagger$ \\
\hline $0-20$ & $-0.10(0.10)$ & $-0.05(0.11)$ & $0.03(0.11)$ \\
\hline$>20-100$ & $0.07(0.09)$ & $0.09(0.10)$ & $0.10(0.10)$ \\
\hline$>100-250$ & $0.23(0.11)$ & $0.25(0.11)$ & $0.24(0.11)$ \\
\hline$>250$ & $0.35(0.19)$ & $0.46(0.20)$ & $0.42(0.20)$ \\
\hline$\beta$ coefficient $(95 \% \mathrm{Cl})$ per $50 \mathrm{mGy}$ & $0.07(0.03$ to 0.11$)$ & 0.07 (0.03 to 0.11$)$ & $0.06(0.03$ to 0.10$)$ \\
\hline$P$ for trend $\ddagger$ & 0.0002 & 0.0003 & 0.0008 \\
\hline
\end{tabular}

${ }^{*}$ Adjusted for number of siblings, age at treatment, year of test, and father's occupation.

†Adjusted for number of siblings, age at treatment, year of test, father's occupation, and high school attendance.

†Based on dose treated as continuous variable.

for the potential confounders $(\mathrm{P}=0.0003)$ but also for high school attendance $(\mathrm{P}=0.0008)$.

\section{Discussion}

External radiotherapy to the head of infants with dose levels that overlap those from computed tomography may adversely affect intellectual development. In Sweden, at the period under investigation, academic performance was the principal determinant of high school attendance. Socioeconomic class was also an important predictor of enrolment at high school, but the inverse association between radiation dose and enrolment at high school persisted after accounting for this and other possible confounders.

Military test results reflecting the difference between learning ability and logical reasoning were affected by the dose of radio- therapy but not influenced by age at treatment, father's occupation, or high school attendance. Furthermore, our a priori expectation that exposure to the frontal part of the brain would have a more severe effect on cognitive function was indirectly supported by the fact that cognitive tests that tap frontal processes seemed to be more affected by radiation. We did not find an influence of age at exposure to ionising radiation, probably due to the narrow age range of 18 months.

On the basis of our findings, it is possible that diagnostic radiation with computed tomography of the head exceeds the individual threshold in several patients. A recent Swedish survey reported an average dose of $68 \mathrm{mGy}$ to the brain of an adult after one computed tomography scan to the head and an estimated $30 \%$ higher dose to a child. ${ }^{23}$ This was confirmed in a recent US study where the estimated dose to an infant exceeded $100 \mathrm{mGy} .{ }^{10}$ In addition, patients may be scanned twice or more. In the West- 


\section{What is already known on this topic}

High doses of ionising radiation to the developing human brain cause mental retardation

It is unknown whether low level exposure in infancy has more subtle effects on cognitive function

\section{What this study adds}

Intellectual development is adversely affected when the infant brain is exposed to ionising radiation at doses equivalent to those from computed tomography of the skull

Diagnostic evaluation of children with minor head injures needs to be re-evaluated

ern world the annual number of computed tomography scans in children may exceed 1.5 million. ${ }^{24}$

Our study has the advantages associated with a cohort design, in which exposure and outcome data are objectively identifiable with uncorrelated errors. The cohort was also large, and losses to follow up were minimal. Moreover, the cohort members did not have diseases such as leukaemia or cancer that could, by themselves or through therapy, confound the results. Lastly, selection bias was minimised as the results relied on internal comparisons rather than on external standards.

The results of other studies are generally compatible with our findings, although earlier investigations have focused on exposures in utero, higher doses, or children with malignancies that could confound the results. In our cohort the risk of central nervous system tumours that could affect brain function was not increased. ${ }^{15}$ Studies of children irradiated for ringworm of the scalp share some similarities with this trial, and their results are generally compatible with our findings. ${ }^{5}$

\section{Conclusion}

Irradiation of the brain with dose levels overlapping those imparted by computed tomography can, in at least some instances, adversely affect intellectual development. Although formal diagnostic protocols do not advocate computed tomography in cases of minor head injuries, clinical practice dictated by legal and financial considerations does not always adhere to these protocols. The risk and benefits of computed tomography scans in minor head trauma need re-evaluating.

Contributors: $\mathrm{PH}$ initiated and planned the study and was mainly responsible for data collection, interpretation of results, and writing the paper. $\mathrm{H}-\mathrm{OA}, \mathrm{DT}, \mathrm{PL}$, and AE participated in the interpretation of results and writing the paper. NLP provided the necessary psychological skills for interpretation of the test results for intelligence, planned the study, and wrote the paper. MI provided the neurocognitive knowledge for interpretation of results and participated in the planning of the project. ML was responsible for dose calculations and planning of the initial phase of the study. FG had overall responsibility for risk analyses and participated in planning and conducting the study. PH and FG will act as guarantors for the paper

Funding: The European Commission (contract No FIGH CT 19990007).

Competing interests: None declared.

Ethical approval: This project was granted ethical approval by the Data Inspection Board in Sweden, 1997.
1 Otake M, Schull WJ. In utero exposure to A-bomb radiation and mental retardation; a reassessment. Br J Radiol 1984;57:409-14.

2 Yoshimaru H, Otake M, Schull WJ, Funamoto S. Further observations on abnormal brain development caused by prenatal A-bomb exposure to ionizing radiation. Int J Radiat Biol 1995;67:359-71.

3 Schull WJ. Brain damage among individuals exposed prenatally to ionizing radiation: a 1993 review. Stem Cells 1997;15(Suppl 2):129-33.

4 Schull WJ, Otake M. Cognitive function and prenatal exposure to ionizing radiation. Teratology 1999;59:222-6.

5 Ron E, Modan B, Floro S, Harkedar I, Gurewitz R. Mental function following scalp irradiation during childhood. Am J Epidemiol 1982;116:149-60.

6 Fogarty K, Volonino V, Caul J, Rongey J, Whitman B, O'Connor D, et al. Acute leukeFogarty K, Volonino V, Caul J, Rongey J, Whitman B, O'Connor D, et al. Acute leuke-
mia. Learning disabilities following CNS irradiation. Clin Pediatr (Phila) 1988;27:524-8. Skowronska-Gardas A. Radiotherapy of central nervous system tumors in young children: benefits and pitfalls. Med Pediatr Oncol 1999;33:572-6.

8 Riva D, Giorgi C. The neurodevelopmental price of survival in children with malignant brain tumours. Childs Nerv Syst 2000;16:751-4.

9 Anderson VA, Godber T, Smibert E, Weiskop S, Ekert H. Cognitive and academic outcome following cranial irradiation and chemotherapy in children: a longitudinal study. Br J Cancer 2000;82:255-62.

10 Brenner D, et al. Estimated risks of radiation-induced fatal cancer from pediatric CT. Am J Roentgenol 2001;176:289-96.

11 Duncan J, Seitz RJ, Kolodny J, Bor D, Herzog H, Ahmed A, et al. A neural basis for general intelligence. Science 2000;289:457-60.

12 Lundell M, Holm LE. Risk of solid tumors after irradiation in infancy. Acta Oncol 1995;34:727-34.

13 Lundell M, Mattsson A, Karlsson P, Holmberg E, Gustafsson A, Holm LE. Breast cancer risk after radiotherapy in infancy: a pooled analysis of two Swedish cohorts of 17,202 infants. Radiat Res 1999;151:626-32.

14 Hall P, Granath F, Lundell M, Olsson K, Holm LE. Lenticular opacities in individuals exposed to ionizing radiation in infancy. Radiat Res 1999;152:190-5.

15 Karlsson P, Holmberg E, Lundell M, Mattsson A, Holm LE, Wallgren A. Intracranial tumors after exposure to ionizing radiation during infancy: a pooled analysis of two tumors after exposure to ionizing radiation during infancy: a pooled analysis of two
Swedish cohorts of 28,008 infants with skin hemangioma. Radiat Res 1998;150:357-64. Swedish cohorts of 28,008 infants with skin hemangioma. Radiat Res 1998;150:357-64.
Kallen B, Karlsson P, Lundell M, Wallgren A, Holm LE. Outcome of reproduction in women irradiated for skin hemangioma in infancy. Radiat Res 1998;149:202-8.

17 Lundell M. Estimates of absorbed dose in different organs in children treated with radium for skin hemangiomas. Radiat Res 1994;140:327-33.

18 Carlstedt B. Cognitive abilities-aspects of structure, process and measurement. University of Gothenburg (Thesis), 2000.

19 National Board of Health and Welfare. Reports on statistical co-ordination. Stockholm: National Board of Health and Welfare, 1982.

20 Lundell M, Furst CJ, Hedlund B, Holm LE. Radium treatment for hemangioma in early childhood. Reconstruction and dosimetry of treatments, 1920-1959. Acta Oncol 1990;29:551-6.

21 Kolb B, Wishaw IQ. Fundamentals of human neuropsychology, 3rd ed. New York: WH Freeman, 1990:412-97.

22 Husen T. The induction test 1944. Requirements and organization. Tidskrift Psykologi Pedagogik 1944;43:114-8. (In Swedish.)

23 Leitz W, Jonsson H. Patient doses from X-rays in Sweden-a summary of results from healthcare reports in 1999. Stockholm: Swedish Radiation Protection Institute, 2001. (In Swedish.)

24 UNSCEAR, United Nations Scientific Committee on the Effects of Atomic Radiation. Sources and effects of ionising radiation. New York: United Nations, 2000.

(Accepted 1 October 2003)

bmj.com 2004;328:19

Department of Medical Epidemiology and Biostatistics, Karolinska Institute, PO Box 281, SE-171 77 Stockholm, Sweden

Per Hall associate professor

Hans-Olov Adami professor

Nancy L Pedersen professor

Anders Ekbom professor

Fredrik Granath biostatistician

Department of Epidemiology, Harvard Center for Cancer Prevention, Harvard

School of Public Health, 677 Huntington Avenue, Boston MA 02115, USA

Dimitrios Trichopoulos professor

Department of Hygiene and Epidemiology, School of Medicine, University of

Athens, Greece

Pagona Lagiou assistant professor

Department of Clinical Neuroscience, Karolinska University Hospital, SE-171 76

Stockholm, Sweden

Martin Ingvar professor

Department of Hospital Physics, Karolinska University Hospital

Marie Lundell hospital physicist

Correspondence to: P Hall

Per.Hall@mep.ki.se 